\title{
Improving the Quality of the COBIT 5 Goals Cascade as an IT Process Prioritisation Mechanism
}

\author{
Dirk Steuperaert, University of Antwerpen, Antwerp \& Ghent University, Ghent, Belgium
}

\begin{abstract}
COBIT 5 is a commonly used IT Governance Framework. Its first principle is that all IT related activities should support generating value for the enterprise. This principle is put in practice through the COBIT 5 Goals Cascade. In this paper the author has researched this principle's main claimed benefit, i.e. that it allows to prioritise IT related processes based on overall enterprise priorities. The quality of the goals cascade was researched by looking at the accuracy of the published mapping tables, the dependencies between goals in the same goal set and the sensitivity of the Goals Cascade towards input variations. The author concludes that the current Goals Cascade isn't very useable as a prioritisation mechanism for IT processes. The author finally proposes an improvement to the current Goals Cascade, consisting of an additional, limited set of 'Enterprise Strategies' that map directly to IT related processes. A prototype solution has been tested, showing promising improvements.
\end{abstract}

\section{KEYWORDS}

COBIT 5 Goals Cascade, COBIT 5, Enterprise Strategies, IT Governance, Prioritisation

\section{PAPER OVERVIEW}

In the COBIT 5 Framework for IT Governance, the Goals Cascade is positioned as a key construct, aimed at putting strategy in practice by prioritising IT enablers, including IT Processes.

This research is an answer to De Haes et al. (2013) in which a call is made for more research on COBIT 5 as an artefact, and hence we will research the Goals Cascade, more precisely whether it is fit for its intended purpose.

In our literature review we found references to the use of the goals cascade and some case studies where the goals cascade was applied. However, no authors challenge the cascade results nor did they customise it. Given this research gap and the unchallenged reliance on the published goals cascade, we believe that further research is highly timely and relevant.

We consider the Goals Cascade as an information item, with a declared goal of assisting in prioritising IT processes based on enterprise goal priorities. Researching an information item for its intended purpose equals researching its quality. Via a short literature review on assessing quality of information, we concluded that the COBIT 5 Information Reference Model provides an adequate information assessment model. We used this model to split up our main research question into several sub-questions. 
First we looked at the intrinsic accuracy of the published goals cascade, by comparing the results of its application with the application of the original research data. We find that intrinsic accuracy is not very high.

Next we discuss the interdependencies between different goals in the same set of goals. We find that enterprise goals in the Goals Cascade are inter-independent. This has a limiting influence on the scoring of those goals in a prioritisation exercise.

As final step of our review, we have run a number of simulations with the published goals cascade to assess its sensitivity for input variations. We find that both in process weight as well as in relative process ranking the current goals cascade is virtually insensitive to input variations. In conclusion, for the reasons aforementioned, we state that the currently published Goals Cascade isn't a very good process prioritisation instrument.

In order to resolve these issues, we define a number of basic requirements for a solution, and we propose the introduction of a new construct in the Goals Cascade, i.e. 'enterprise strategies', and we defined a limited set of four generic enterprise strategies.

We have performed a proof of concept study for this new construct, including an initial assessment of the viability of the new construct, the initial population of a new mapping table between enterprise strategies and IT processes, and for a high-level assessment of contingencies. The result of our proofof-concept study is promising, and shows a substantially higher sensitivity for input variations, making it a potentially superior prioritisation instrument compared to the current Goals Cascade.

\section{PROBLEM STATEMENT}

\subsection{COBIT 5 Goals Cascade}

A number of IT Governance Frameworks have been developed over the last decades to help organisations obtain value from their investments in IT. One of the commonly used Frameworks is COBIT, of which the most recent version (COBIT 5) was released in December 2012 by ISACA. The COBIT 5 Framework is based upon 5 principles, and this paper is about the first COBIT 5 principle: "1. Meeting Stakeholder Needs", and the key mechanism by which it is put in practice, i.e. the Goals Cascade.

The first principle, with the Goals Cascade, is described in COBIT 5 (2012, p.17-22 and Appendix B through D). The Goals Cascade itself is described as "The COBIT 5 goals cascade is the mechanism to translate stakeholder needs into specific, actionable and customised enterprise goals, IT-related goals and enabler goals. This translation allows setting specific goals at every level and in every area of the enterprise in support of the overall goals and stakeholder requirements, and thus effectively supports alignment between enterprise needs and IT solutions and services." (COBIT 5, 2012). The principle of the Goals Cascade is depicted in Figure 1.

Figure 1 also illustrates that the Goals Cascade consists of two types of constructs: (1) lists of goals: enterprise goals, IT Related goals, enabler goals (instantiated by process goals), and (2) mapping tables expressing the relationship between two levels of goal lists, typically in the form of $\mathrm{n} \times \mathrm{m}$ matrices, with each matrix element $\mathrm{m}_{\mathrm{i}, \mathrm{j}}$ expressing the relationship between higher-level goal $\mathrm{i}$ and lower-level goal $\mathrm{j}$. All mapping tables use a similar scale for $\mathrm{m}_{\mathrm{i}, \mathrm{j}}$ : ' $\mathrm{P}$ ' for Primary (a goal is a primary contributor to another goal), ' $\mathrm{S}$ ' for Secondary (a goal is a secondary contributor to another goal) and blank.

The Goals cascade principle is then put in practice in COBIT 5 by (1) A mapping between enterprise goals and the value dimensions - benefits, risk \& resources, (2) A list of 17 generic enterprise goals, structured as per the Balanced Scorecard dimensions, (3) A mapping table between enterprise goals and IT related goals (COBIT 5, 2012, Appendix B), (4) A list of 17 generic IT related goals, structured as per the Balanced Scorecard dimensions, and (5) A mapping table between IT related 


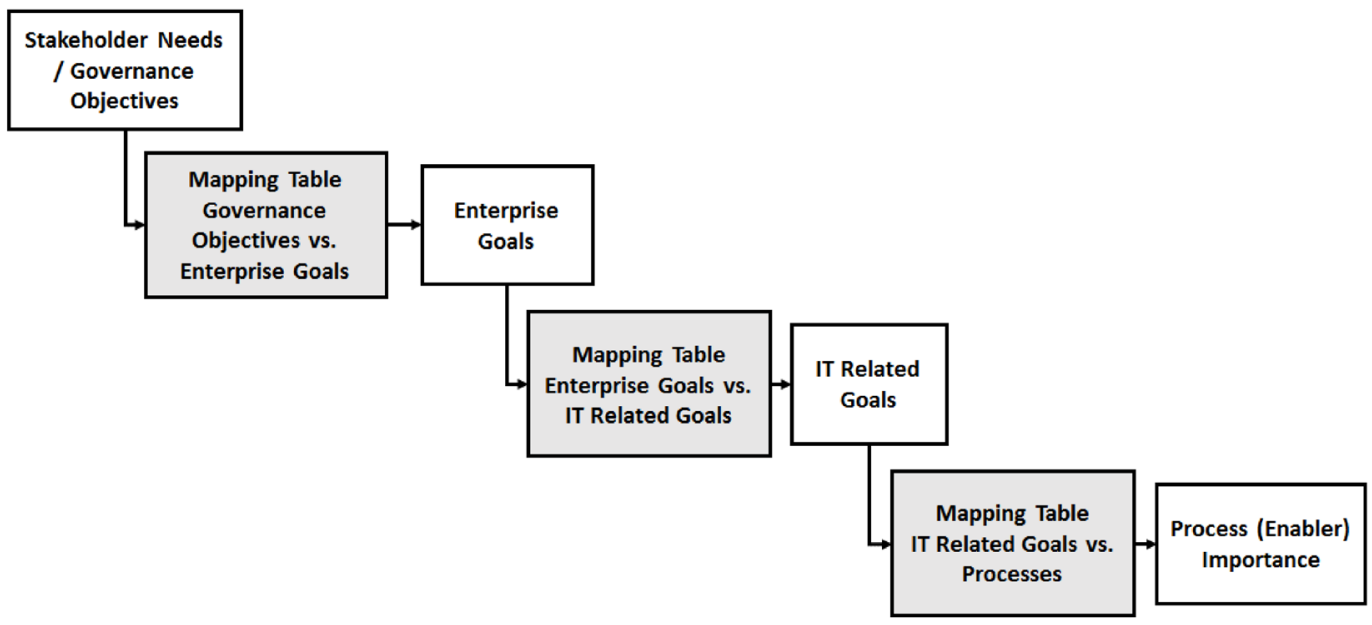

goals and COBIT 5 Processes, as defined in the COBIT 5 Process Reference Model (COBIT 5, 2012, Appendix C); COBIT 5: Enabling Processes, 2012)

For this research we focus on the main published mapping tables (3) and (5) in above list. These published mapping tables are based on original research by a research group at Antwerp University, surveying a panel of experts. $(\mathrm{N}=34)$. The survey probed the following question: 'does the goal $\mathrm{X}$ (from the mapping dimension) support the achievement of the goal Y (from the mapped dimension)?' The mapping results thus obtained are percentages between $0 \%$ and $100 \%$, corresponding to the percentage of respondents who answered positive to each combination. The mapping tables were then processed and reviewed before publication, by reducing the mapping results to three discrete values, Blank, S (Secondary) and P (Primary).

\subsection{Claimed COBIT 5 Goals Cascade Benefit}

In De Haes et al. (2013), an argument is made for further research on COBIT 5 as an artefact. The prominent place of the Goals Cascade in the COBIT 5 Framework makes it a relevant artefact for research. Indeed, COBIT 5 claims that the main use and benefit of the Goals Cascade is that it allows to prioritise processes and other enablers, based on high-level stakeholder needs. (COBIT 5, 2012, p.20).

The COBIT 5 authors, also include a disclaimer, stating that "The goals cascade-with its mapping tables between enterprise goals and IT-related goals and between IT-related goals and COBIT 5 enablers (including processes)—does not contain the universal truth, and users should not attempt to use it in a purely mechanistic way, but rather as a guideline." (COBIT 5, 2012, p.20)

The disclaimer is followed by guidance on how to apply the Goals Cascade concept in one's own organisation, (COBIT 5, 2012, p.20), but it does not include guidance on how and where such a customised mapping should be made. In this paper we consider the assumption that one can define interlinked goals at different levels of an organisations to be valid. We justify this assumption because the current sets of goals in the Goals Cascade are based on Balanced Scorecard principles, and because earlier research (De Haes et al., 2016; Y. Bartens et al, 2015) has confirmed the alignment between the different levels of goals. 
International Journal of IT/Business Alignment and Governance

Volume $7 \cdot$ Issue $2 \cdot$ July-December 2016

\subsection{Problem Statement Conclusion}

We performed an exploratory search for available literature on 'COBIT 5', 'Goals cascade' and/or 'enterprise goals'. A limited set of papers and articles were found from both industry journals and academic journals and conferences.

From our search we learnt that (a) a number of papers mention the existence of the goals cascade and explain its functioning, without challenging or customising it (Iskandar et al, 2010), (b) some papers include case studies, again using the Goals cascade, without challenging or apparent customisation (Bartens, 2014; Laksonto et al., 2015; Y. Supriyadi, 2015; A. Romadhona et al, 2015), (c) some papers use an unmodified goals cascade as foundation for further research, e.g. building a formal ontology (Textor et al, 2015), and (d) there was no literature found challenging the concept or quality of the current Goals cascade. (De Haes et al., 2013; Mangalaraj, 2014)

So the problem we are faced with is that the generally accepted COBIT 5 Framework contains an important construct - the Goals Cascade - which claims an important benefit, but nowhere is this claim confirmed or challenged in literature. This is an important gap, given the (overly?) high reliance organisations put on this construct; the call for more research in De Haes et al. (2013) on COBIT as an artefact has remained unanswered yet for at least the Goals Cascade.

\section{RESEARCH QUESTIONS}

\subsection{Introduction and Definitions}

Considering the problem statement, the prime goal of this paper then becomes to research whether the current goals cascade is fit for its intended purpose, which is to support prioritisation of IT processes. If necessary, an improvement will also be proposed.

Before describing detailed research questions, we first need to define what 'prioritisation' of a process means, and what 'fit for purpose' means in our context.

Prioritisation of a Process: Prioritisation of a Process means that within the context of the enterprise to which the Goals Cascade is applied, processes are ranked from most critical to least important.

This ranking requires quantification of the importance of a process, expressed as an absolute weight, as a normalised weight (e.g. on a scale to 100), or as a relative ranking index.

'Fit for purpose' Goals Cascade: 'fit for purpose' is a very often used description of quality. If we consider the Goals Cascade to be an information item, we thus need to assess the quality of this information item. Looking for Information Quality research, in Mai (2013), the author essentially splits information quality criteria in intrinsic and contextual criteria, when a comprehensive quality assessment needs to be made. In COBIT 5 there is also information quality related guidance in the form of an information reference model that includes a set of criteria to measure the quality of an information item. [1, p.81] and COBIT 5 Enabling Information, (ISACA, 2014). The COBIT 5 Information Reference Model contains 15 quality criteria, and groups them in intrinsic, contextual and accessibility categories, i.e. well in line with Mai (2013). For that reason, we have used the COBIT 5 Information Reference model to develop our more detailed research questions. One could note here that we are assessing a COBIT 5 artefact (the goals cascade) by its own COBIT 5 criteria.

\subsection{Research Questions}

Based on the above, we have defined the following detailed research questions:

1. Accuracy: Is the Goals Cascade accurate? Our proposition is that "The reduction of the underlying research data on the Goals Cascade into the published mapping tables in the Goals Cascade results in a significant accuracy reduction of the resulting process priorities. " 
2. Ease of Manipulation: Does the Goals Cascade allow easy prioritisation at the input side. Our proposition is that "the current set of enterprise goals contains interdependencies preventing independent goal prioritisation. "

3. Relevancy, Appropriate Amount of Information: Does the Goals Cascade demonstrate sufficient sensitivity for process prioritisation? Our proposition is that "the current Goals Cascade mechanism is not sensitive enough to allow proper process prioritisation"

4. A last question looks into potential improvements to resolve observed deficiencies. Our Propositions are (a) "It is possible to complement the current Goals Cascade with a new, more accurate construct with fewer internal dependencies". (b) "It is possible to define a direct and meaningful mapping between the new construct and the IT processes" and (c) "It is possible to use the direct mapping as a more sensitive process prioritisation mechanism compared to the current Goals Cascade."

Some remarks on the selected research questions:

1. We believe the selected questions cover a representative subset of quality criteria; however, we did not include all criteria in our detailed research questions for the sake of time. Non-selected criteria are candidates for further research, and this applies particularly to another aspect of the 'relevance' criterion, i.e. the validity of the current Goals Cascade which is also linked to the 'Objectivity' and 'Believability' criteria;

2. One could argue that the use of the COBIT Information Model is a quite convoluted way to define detailed research questions on an in essence relatively simple topic; however, the main benefit and use of a 'reference' model is that (1) this model is our theoretical reference, and (2) by using such a model one will always obtain an additional level of assurance over the completeness of their approach, hence this 'detour'.

\section{METHODOLOGY}

The following research approach was applied for the four detailed research questions:

Research Question 1 on Accuracy of the Goals cascade: we analyse the effect of the two sets of mapping tables - the research data and the published versions - on the outcome of the goals cascade, i.e. process priorities. The size of this impact will be an indicator of the inherent accuracy of the Goals Cascade.

We will run a simulation, where the mapping tables are the independent variables and the resulting process weights the dependent variable. In our simulation we feed the same input (a [1x17] matrix, representing the priorities of each of the generic enterprise goals as defined in COBIT 5, where each goal is deemed equally important.) to both sets of mapping tables and compare the output of the Goals Cascade (a [1x34] matrix, containing the resulting weights of each COBIT 5 process, obtained through multiplication of the input matrices with both mapping tables, except for the 3 processes for which no research data were available ${ }^{1}$. This is represented graphically in Figure 2. The resulting weights are normalised on a scale of 100.)

Research Question 2 on Goals Inter-dependencies: We have used analytical review and peer review on a subset of enterprise goals and assess whether there exist dependencies between enterprise goals.

Research Question 3 on Goals Cascade Sensitivity: we will perform a simulation of the Goals Cascade and observe two dependent variables of the Goals Cascade: (a) The resulting process weight, normalised on a scale of 10, and (b) the relative process ranking in the ranked list of all 37 COBIT 5 processes.

The independent variable in our simulations are the priorities for the Enterprise Goals, i.e. a [1x17] matrix of priorities, expressed as an integer between 1 (low priority) and 3 (high priority). We have made two simulations: (1) a limited simulation where we included 17 cases, each time 
International Journal of IT/Business Alignment and Governance

Volume $7 \cdot$ Issue $2 \cdot$ July-December 2016

Figure 2. Goals cascade accuracy analysis

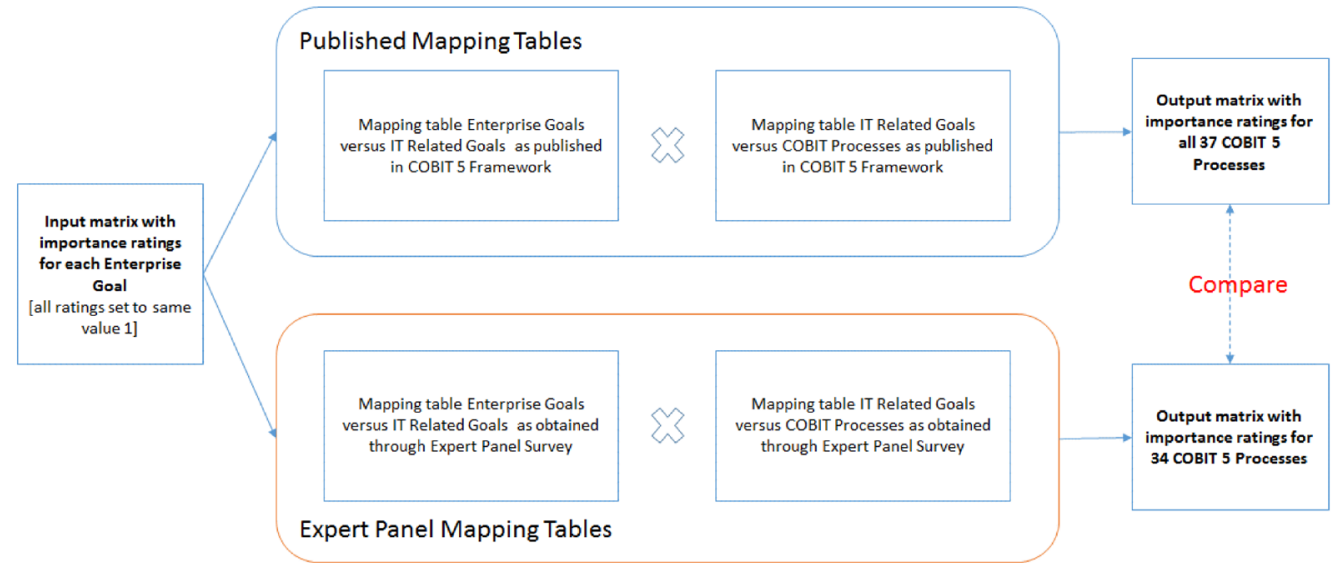

setting one enterprise goal priority at high priority and leaving the others at low priority, and (2) a larger simulation where we included 2500 cases with random variations of enterprise goal priorities.

Research Question 4 on proposed improvements: The approach we have taken for this part of the research (and this part only) is a design-science based approach. A first validation of the new artefact has been performed by an expert panel.

\section{RESEARCH RESULTS}

\subsection{Research Question 1: Accuracy of the Goals Cascade}

The results of the comparison are shown in Figure 3 and Figure 4.

Figure 3 shows a spider chart that contains two sets of values: (1) The process weights obtained through the application of the published COBIT 5 Goals Cascade, and (2) The process weights obtained through the application of the Goals Cascade with the original research data.

Figure 4 shows the relative differences, expressed as a \%, between resulting processes weights obtained through application of the Goals Cascade using both sets of mapping tables.

The results of the comparison between the application of both sets of mapping tables shows that the resulting weights from application of the goals cascade using the two different mapping table sets are similar, but that there are also some significant deviations, as summarised in Table 1.

The maximum observed difference is $42 \%$, for the process MEA3. The average absolute value of the deviation between normalised process weights is 8.3 , the median value is 7.0 , corresponding with relative deviations of on average $11 \%$, and with a median of $9 \%$.

We then looked into the ranking differences of the processes as a result of the application of both sets of mapping tables.

We observed some important differences between the uses of both sets of mapping tables, in line with the results of the comparison of process weights; $41 \%$ of the processes have a ranking difference higher or equal than 5, which we consider to be a significant impact. This is depicted in Figure 5 and summarised in Table 2.

\subsection{Research Question 2: Goals Interdependencies}

When the Goals Cascade is used as a prioritisation mechanism, one requirement is that the set of input values to the Goals Cascade must be easily 'scoreable', i.e. it must be possible to assign different 
Figure 3. Goals cascade accuracy analysis - process weights

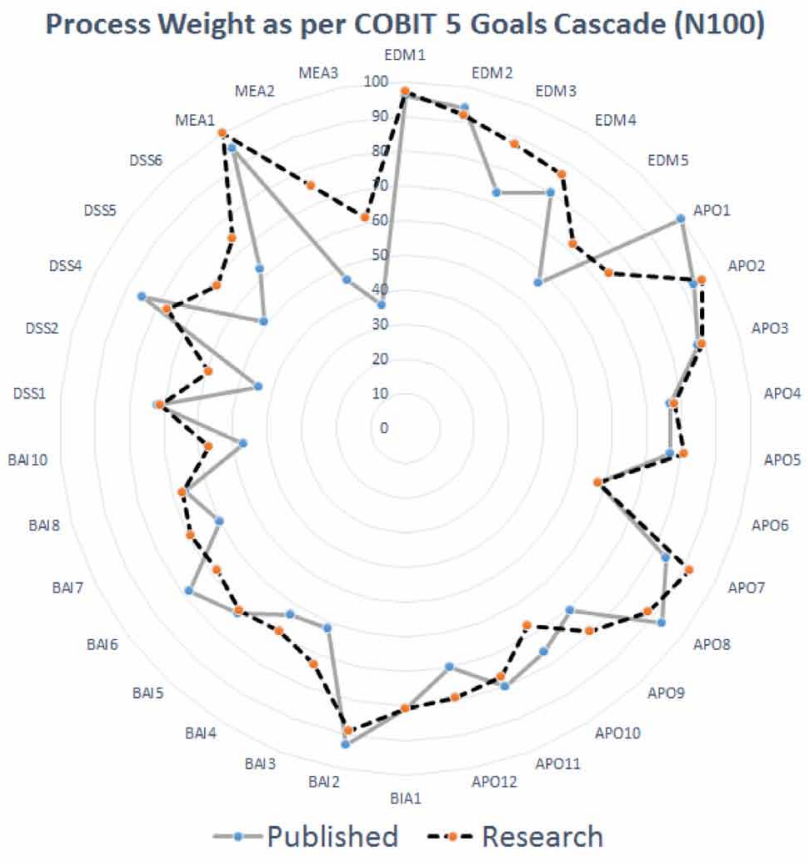

Figure 4. Goals cascade accuracy analysis - process weights $\%$ deviations

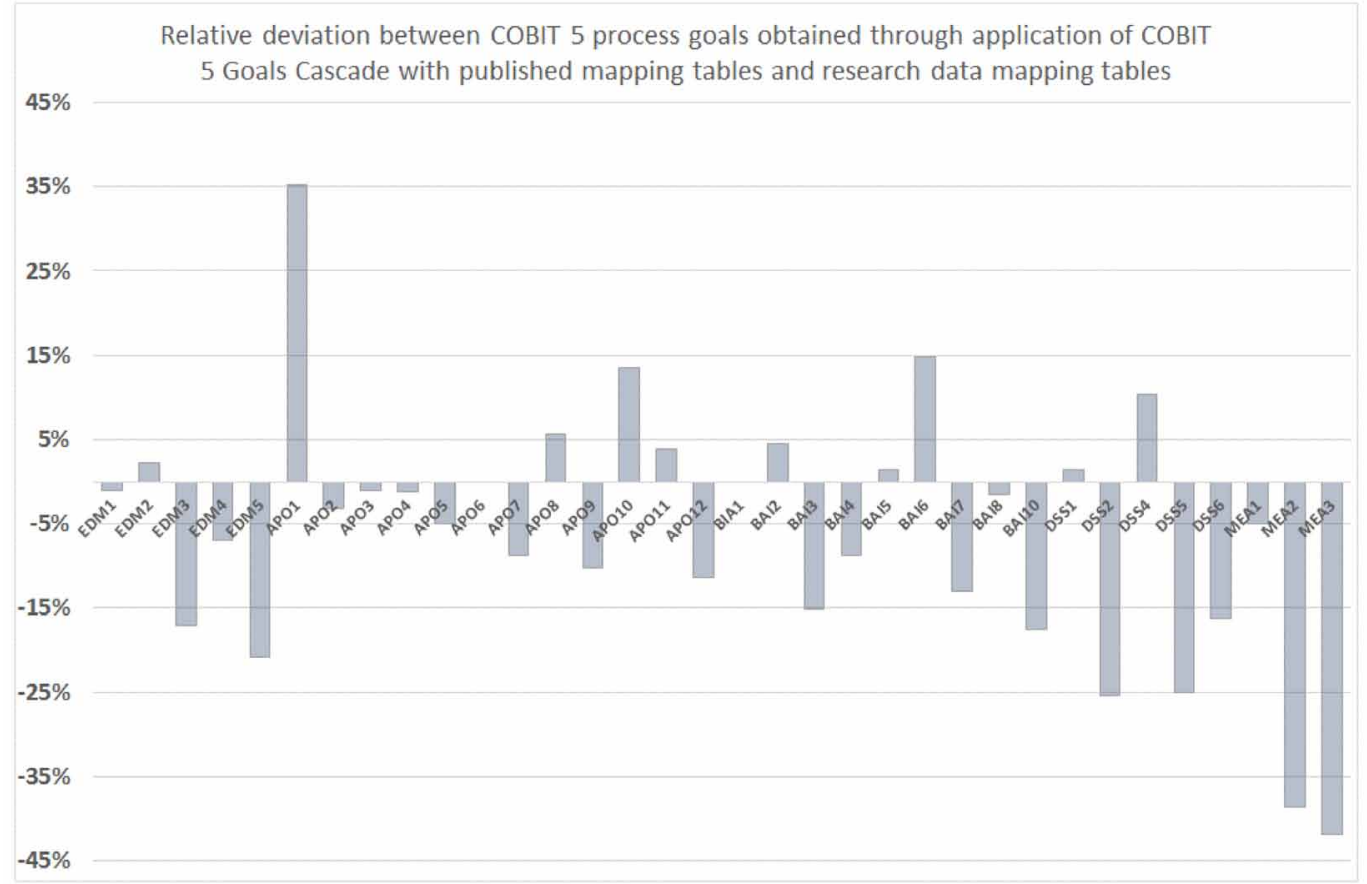


International Journal of IT/Business Alignment and Governance

Volume 7 • Issue 2 • July-December 2016

Table 1. Deviation of process weights

\begin{tabular}{|l|l|l|}
\hline \multicolumn{1}{|c|}{ Deviation } & \multicolumn{1}{c|}{ \#Processes } & \multicolumn{1}{c|}{ \%Processes } \\
\hline Less than 5\% & 13 & $38 \%$ \\
\hline Between $5 \%$ and $10 \%$ & 5 & $15 \%$ \\
\hline Between $10 \%$ and $15 \%$ & 6 & $18 \%$ \\
\hline More than $15 \%$ & 10 & $29 \%$ \\
\hline
\end{tabular}

Figure 5. Goals cascade accuracy analysis - ranking differences

\section{Process Ranking Difference between application of published goals cascade versus research mapping tables}

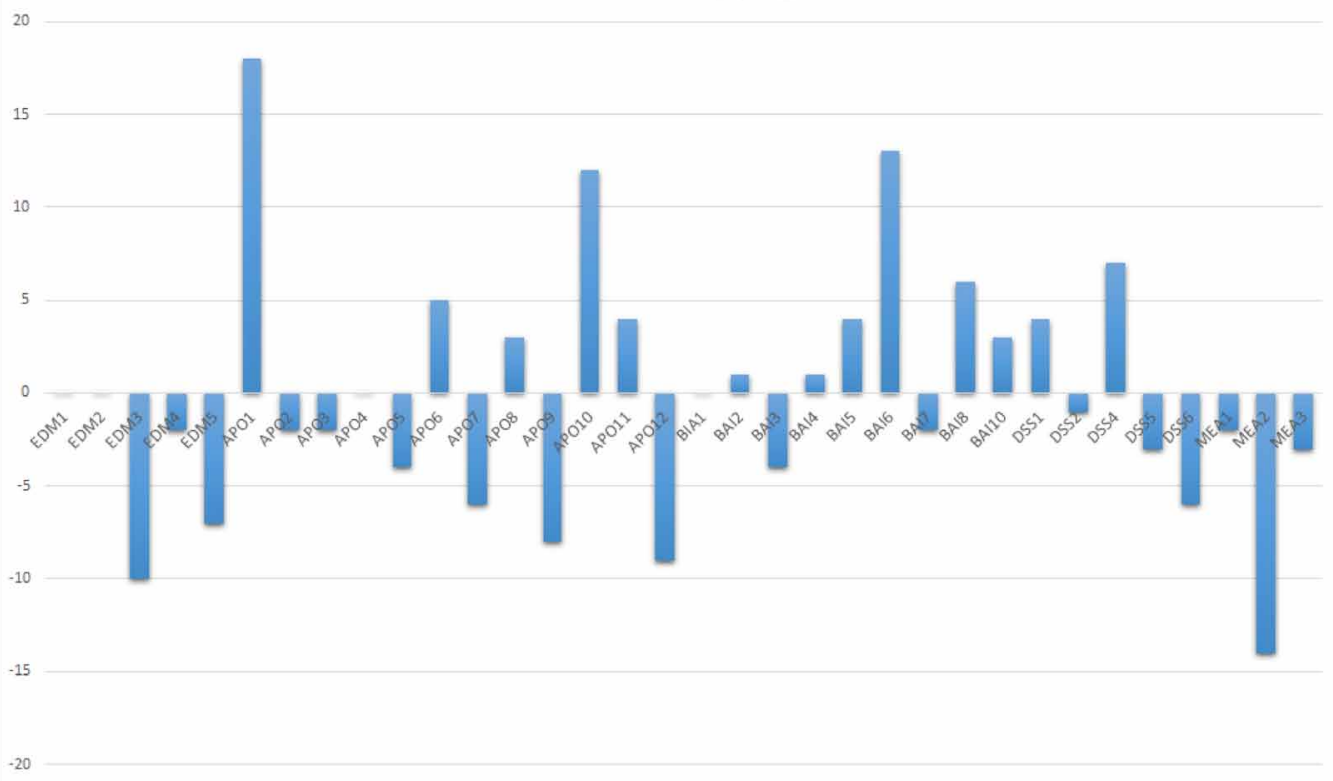

Table 2. Deviation of process ranking

\begin{tabular}{|l|l|l|}
\hline \multicolumn{1}{|c|}{ Deviation (\# positions) } & \multicolumn{1}{|c|}{ \#Processes } & \multicolumn{1}{c|}{ \%Processes } \\
\hline Less than 5 & 22 & $59 \%$ \\
\hline Between 5 and 10 & 8 & $22 \%$ \\
\hline Between 10 and 15 & 3 & $8 \%$ \\
\hline More than 15 & 4 & $11 \%$ \\
\hline
\end{tabular}

and independent scores to each goal listed in the complete set. This requirement is perhaps not as straightforward as it seems, because independent scoring, requires that there are no dependencies between Goals. As soon as Goals become interdependent, independent scoring becomes less meaningful or potentially impossible. 
Table 3. Enterprise goals dependencies

\begin{tabular}{|l|l|l|l|l|l|l|l|l|l|}
\hline $\begin{array}{c}\text { Goals } \\
\text { Interdependencies }\end{array}$ & EG02 & EG03 & EG04 & EG05 & EG06 & EG07 & EG08 & EG09 & EG10 \\
\hline EG01 & H & H & $?$ & H & H & H & H & & $?$ \\
\hline EG02 & & & & H & H & H & H & H & H \\
\hline EG03 & & & H & $?$ & & H & H & $?$ & \\
\hline EG04 & & & & H & & $?$ & $?$ & $?$ & $?$ \\
\hline EG05 & & & & & & & & H & $?$ \\
\hline EG06 & & & & & & H & H & H & H \\
\hline EG07 & & & & & & & $?$ & $?$ & \\
\hline EG08 & & & & & & & & H & \\
\hline EG09 & & & & & & & & & \\
\hline
\end{tabular}

Dependency of hierarchical relationships between elements in a set of goals is inherently not a bad thing - it can help to understand and assess alignment and achievement of goals, but in this context it would prevent independent prioritisation.

Since the sets of goals in the Goals Cascade are built using the Balanced Scorecard (BSC) structure, and since the BSC inherently and almost by design contains interdependent goals, it is a no-brainer that the goals in the Goals Cascade will be interconnected.

Yet we wanted to validate this assumption, and took a subset of the Enterprise Goals (COBIT 5, 2012, p19) and had four researchers from our research group independently assess interdependencies. The result is shown in Figure 2, highlighting a substantial number of interdependencies. Some relationships were unclear (indicated by '?'), but we did not pursue this further given the fact we demonstrated our point already.

\subsection{Research Question 3: Goals Cascade Sensitivity}

One key criterion for the Goals Cascade to be usable as a prioritisation mechanism is that it is sensitive enough, i.e. that sufficient output variation will need to be obtained when input variations are applied. The minimum requirement is that sensitivity consistently exceeds inherent inaccuracy for all processes. The results of the simulations are shown in Figure 6 and in Figure 7, where we show the outcome of both dependent variables - process weight and process ranking for the large simulation.

Table 4 contains a brief summary of the results of both simulations for both dependent variables:

\subsection{Research Question 4: Improving the usability of the Goals Cascade - a Proof of Concept}

\subsubsection{Introduction and Rationale}

Figure 1 depicted the current Goals Cascade logic. In the previous sections we established issues with the current Goals Cascade, i.e. (1) the published Goals Cascade is inherently inaccurate, (2) the current set of enterprise goals and IT related goals are not (sufficiently) orthogonal, preventing logical prioritisation of goals and (3) the current goals cascade lacks sensitivity.

In the remainder of this section we propose a solution to the aforementioned issues, and develop this proposed solution as a proof of concept.

The proposed solution would then need to satisfy at least the following criteria: (a) reduce the impact of inter-dependencies between construct values, either by reducing their number, or by otherwise taking into account inter-dependencies when prioritising, and (b) show adequate sensitivity for variations in the new construct's values. 
International Journal of IT/Business Alignment and Governance

Volume 7 •Issue 2 • July-December 2016

Figure 6. COBIT 5 process weight range after goals cascade application $(\mathrm{N}=2500)$

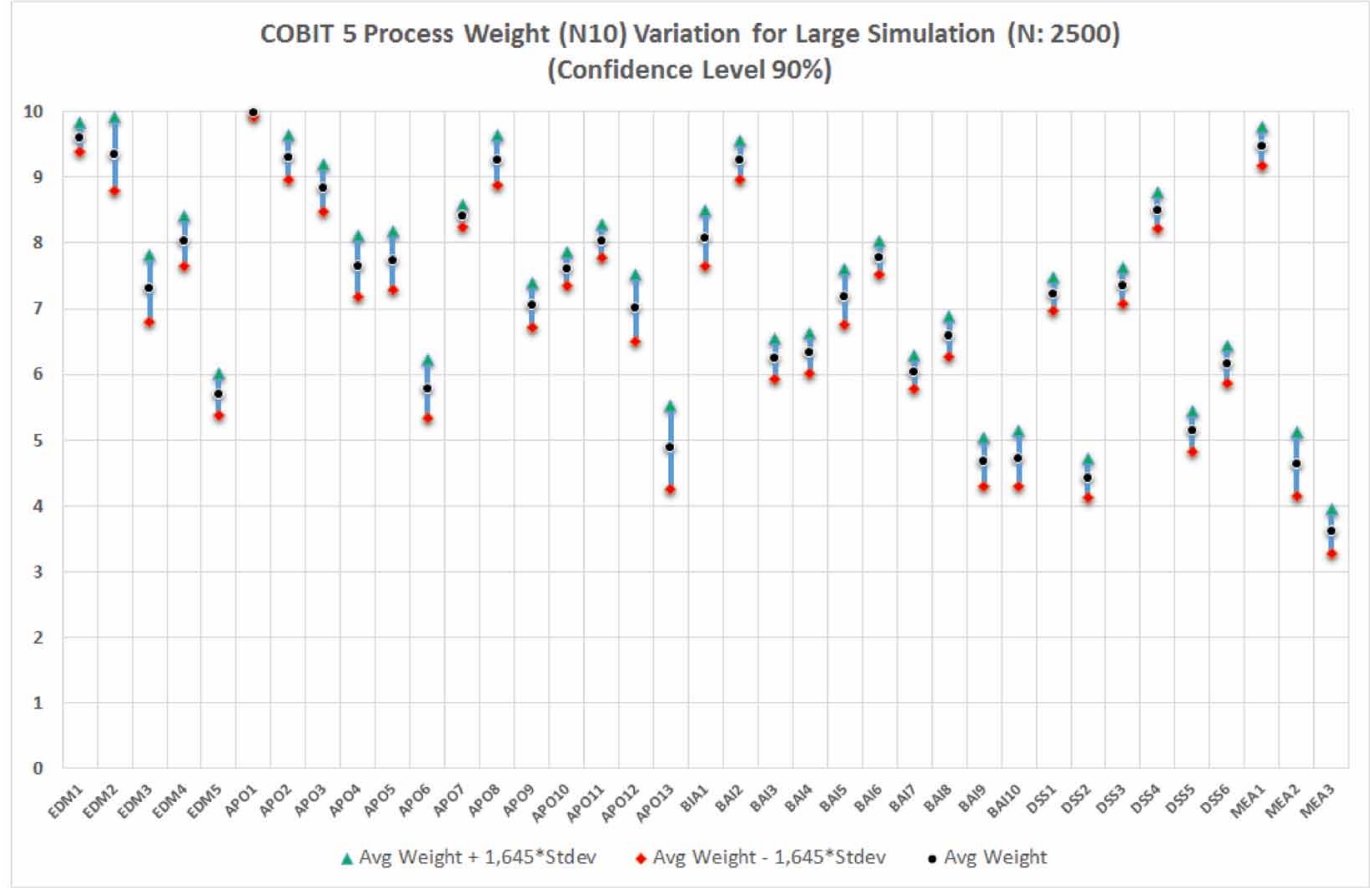

Figure 7. COBIT 5 process ranking range after goals cascade application $(\mathrm{N}=\mathbf{2 5 0 0})$

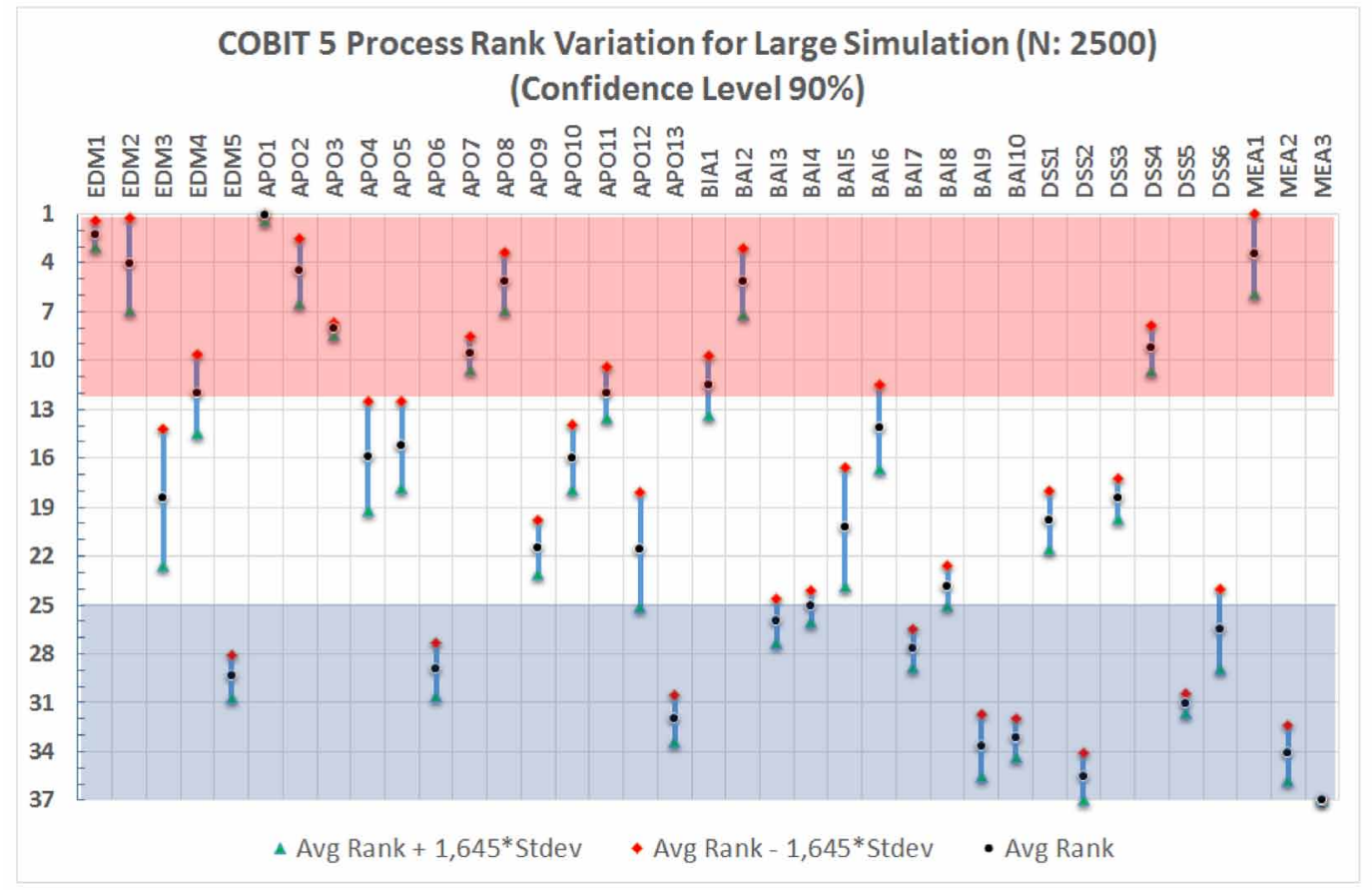


Table 4. Overview sensitivity simulations

\begin{tabular}{|l|l|l|}
\hline & \multicolumn{1}{|c|}{$\begin{array}{c}\text { Single Goal Variation } \\
\text { (Min-Avg-Max) }\end{array}$} & \multicolumn{1}{|c|}{$\begin{array}{c}\text { Random Goals Variation } \\
\text { (Min-Avg-Max) }\end{array}$} \\
\hline Absolute Deviation Weight & $0.1-0.8-1.5$ & $0.6-1.3-2.5$ \\
\hline Ranking Spread & $0-3.7-9$ & $3-7.4-15$ \\
\hline
\end{tabular}

Table 5. Generic enterprise strategies (proposed)

\begin{tabular}{|c|c|c|}
\hline Ref & Strategy & Justification \\
\hline ES01 & Growth/Acquisition Strategy, i.e. the enterprise has a focus on growing (revenues) & $\begin{array}{l}\text { Corresponds with 'prospectors' (Miles } \\
\text { \& Snow) }\end{array}$ \\
\hline ES02 & $\begin{array}{l}\text { Innovation/Differentiation, i.e. the enterprise has a focus on offering different and/or } \\
\text { innovative products and services to their clients }\end{array}$ & $\begin{array}{l}\text { Corresponds with visionary and } \\
\text { shaping (Reeves) } \\
\text { Corresponds with differentiation } \\
\text { (Porter) } \\
\text { Corresponds with product leadership } \\
\text { (Treacy) }\end{array}$ \\
\hline ES03 & Cost Leadership, i.e. the enterprise has a focus on short-term cost minimisation & $\begin{array}{l}\text { Corresponds to Cost Leadership } \\
\text { (Porter) } \\
\text { Corresponds with operational } \\
\text { excellence (Treacy) }\end{array}$ \\
\hline ES04 & $\begin{array}{l}\text { Client Service/Stability, i.e. the enterprise has a focus on providing a stable and client oriented } \\
\text { service. }\end{array}$ & $\begin{array}{l}\text { Corresponds with defenders (Miles } \\
\text { \& Snow) } \\
\text { Corresponds with classical (Reeves) } \\
\text { Corresponds with focus (Porter) } \\
\text { Corresponds with customer intimacy } \\
\text { (Treacy) }\end{array}$ \\
\hline
\end{tabular}

The proposed solution would thus include

1. A (new) construct in the goals cascade (comparable to e.g. the construct 'enterprise goals'),

2. A set of values for the new construct (comparable to e.g. the 17 generic enterprise goals from COBIT 5 (2012), and

3. A mechanism to link the new construct to existing constructs (comparable to the current mapping tables in COBIT 5 (2012).

\subsubsection{Newly Proposed Artefact: "Enterprise Strategies"}

The most logical place to start looking for clues or suggestions for a new construct is of course COBIT 5 itself. In COBIT 5 (2012) we read at the beginning of the goals cascade chapter that "Stakeholder needs have to be transformed into an enterprise's actionable strategy", making a reference to enterprise strategy. More references to enterprise strategy are made in COBIT 5 (2012), e.g. (a) where the Balance Scorecard-(BSC) based structure of the enterprise goals is explained, and (b) when looking at IT related goal 01 "Alignment of IT and business strategy". This makes 'enterprise strategy' an interesting candidate for a new construct.

Kaplan in Norton (2004) also make the link between their Balanced Scorecard (as strategic measurement instrument) concepts and how it can be mapped to different aspects of the enterprise strategy (strategy maps). Because the BSC-based set of enterprise goals is already part of the Goals cascade, and because the close link between BSC and enterprise strategy, we propose to retain the construct 'enterprise strategy' as a potential candidate solution. Many definitions of strategy exist for now we would refer to Ansoff (1965): "what are the firm's objectives and goals; should the firm 
seek to diversify, in what areas, how vigorously; and how should the firm develop and exploit its present product-market position"

Next is to determine how we are going to connect it to the existing constructs from the current Goals Cascade. In order to come to an adequately sensitive process prioritisation mechanism, we propose to map the enterprise strategies construct directly to the existing COBIT Processes. At the same time there needs to be adequate consistency between the new construct 'enterprise goals' and the existing 'enterprise goals' and/or the 'value objectives' construct. We focused on direct mapping between enterprise strategies and processes to validate the proof of concept. A mapping between Enterprise Strategies and other constructs, e.g. 'value objectives' or 'enterprise goals' was not undertaken as part of the proof-of-concept. This can be part of a more thorough validation in subsequent research (see Figure 8).

The final step in our proposition is to populate the new 'enterprise strategies' construct with potential values, i.e. a set of generic strategies an enterprise can pursue.

A plethora of literature has been produced on business strategies and their typologies, e.g.

1. Miles and Snow (2003) distinguish between prospectors, defenders, analyzers and reactors.

2. Reeves et al. (2015) describe a typology with five strategy types: classical, adaptive, visionary, shaping, and renewal.

3. Porter (1980) distinguishes between cost leadership, differentiation and focus strategies.

4. Variants of the latter then describe operational excellence, product leadership and customer intimacy (Treacy, \& Wiersema, 1993)

5. We also looked at the resource based view theories (add ref), but found that the concepts developed there (resources, capabilities) probably better match the 'enabler' concept as it is developed in COBIT 5, which means that they are deployed to realise strategies rather than being strategy options in themselves.

Trying to synthesize these referenced approaches into a small set of generic enterprise strategies in function of the validation of our proof-of-concept, we have defined the following set of four potential enterprise strategies (or hybrid combinations thereof) that any organisation could pursue; this is shown in Table 5, which contains the name of the generic enterprise strategy, a brief explanation, and a brief

Figure 8. Proposed goals cascade scheme

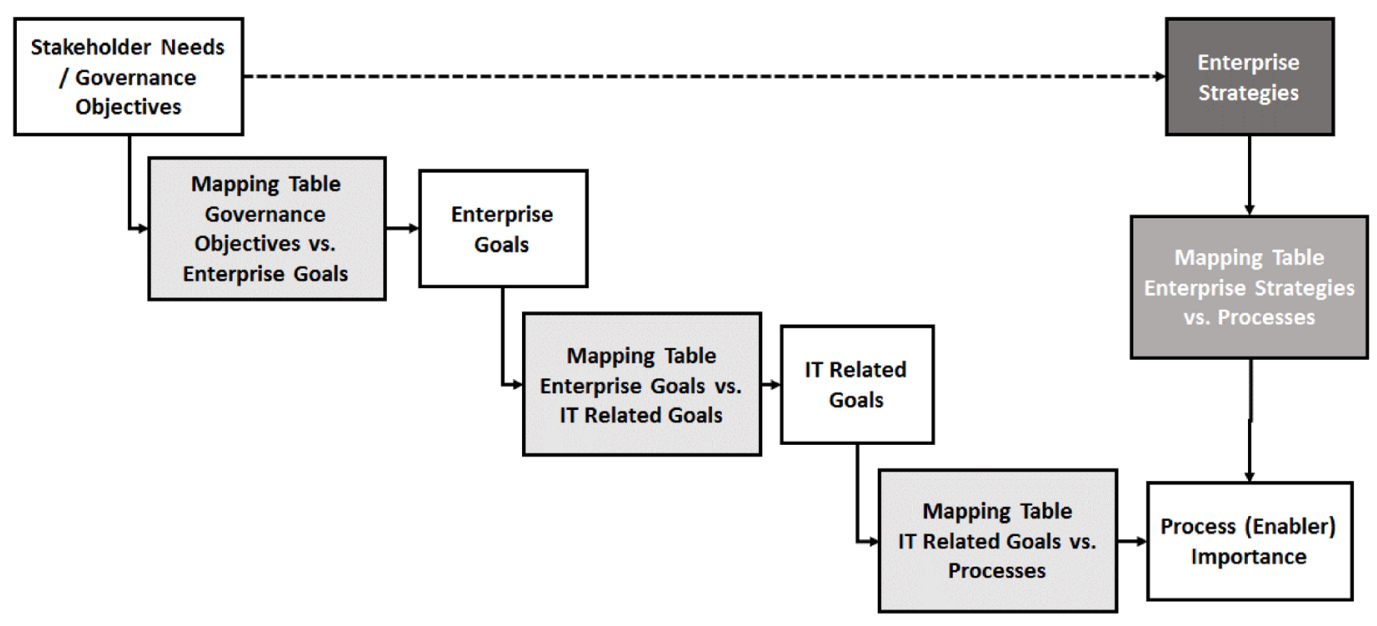


justification under the form of a mapping with a number of the different strategies mentioned above. Please note that the mapping does not map to all possible strategy options identified above, which will require a deeper analysis during follow-on research.

Given its popularity and multiple references, we also compared our proposed list with the Blue Ocean strategy thinking (add ref); we argue that essentially Blue Ocean strategies are a combination of Innovation/Differentiation (ES02) and also Cost Leadership (ES03), hence we see no conflict with our proposed set of generic enterprise strategies.

The above prospective list of enterprise strategy options is not fully validated; we believe that since this is still a proof of concept stage of the design this should not pose a problem for now.

\subsubsection{Initial Validation of Proof of Concept}

As stated above, we want to introduce a direct mapping between the table of enterprise strategies (Table 5) and the COBIT 5 processes, expressing to what extent a process supports a given enterprise strategy.

In order to validate the concept of the proposed solution, and in order to initially populate the new mapping table, we worked with a limited expert panel who were given a questionnaire to map each of the four enterprise strategies to the COBIT 5 processes.

The respondents of the survey were a number of technology and governance professionals, all active as consultant. They have (a) Between 5 and 30 years' experience in the area of IT Governance, IT Risk Management, Technology Consulting, (b) Understanding of IT Governance Frameworks, including COBIT 5 (c) Having mixed experience with the use of the COBIT 5 Framework in practice, i.e. not all panel members are COBIT experts, providing for a less biased view.

All members of the panel experts were asked to assign an importance rating to each of the 37 COBIT 5 processes for each of the four enterprise strategies defined above. For processing convenience, we assigned a numeric value to these ratings. The four possible ratings and their numerical weights for the process importance were: Critical (10), Important (7), Normal (4), Less Important (1)

Respondents were asked to identify at least two processes in each of the extreme categories, in order to force a minimum spread between the process ratings.

Given that this is still a proof of concept of a new construct, the size of the expert panel was kept limited $(\mathrm{N}=9)$. As described in the future research section, this panel needs to be extended significantly for a further confirmation study. The current exercise can be seen as the first stage in a Delphi research approach, of which the next stages will be executed in the follow-on research. This will further validate our proposed solution.

The results from the expert panel were analysed, and findings were as follows: first of all, the panel did not report any major difficulty in completing the survey, thus indicating that the direct mapping between enterprise strategies and processes is a viable mapping, not creating any conceptual difficulties.

The detailed results of the mapping survey are shown below: the raw mapping table results are shown in Table 5 - Mapping Table between Enterprise Strategies and COBIT 5 Processes, showing the weight (score on a scale 1-10) of each process, per enterprise strategy.

When applying this mapping table we observe larger variations - when compared to the current published Goals Cascade - between highest and lowest process weights, indicating that differences or variations in enterprise strategies will influence process importance. Some detailed observations:

1. The average difference between minimum and maximum weight for the same process between enterprise strategies is 2.4 on a scale to 10 , compared to an average difference of 1.3 for the current Goals Cascade (see Table 4).

2. The maximum difference observed between minimum and maximum weight for one process is 6,33 (process APO04 - Manage Innovation), or almost two rating levels apart, indicating that the importance of this processes will heavily depend on the chosen enterprise strategy. This compares to a maximum difference of 2.5 for the current Goals Cascade (see Table 4). 
3. The minimum difference observed between minimum and maximum weight for one process is 0,66 (process MEA03 - Monitor, evaluate and assess compliance with external requirements), indicating that the importance of this processes is quite constant, irrespective of the enterprise strategy.

Our second dependent variable is the relative process ranking, depicted in Figure 9, where the range of ranks for each process across enterprise strategies is shown.

\subsubsection{Contingencies}

We asked the expert panel also to what extent they would change any of their mappings for any of the enterprise strategies, depending on (1) industry sectors, and (2) organisation size.

We found that nobody expects a major impact ( $>30 \%$ changes) on mapping values (Table 5) from organisation size and/or industry sector, and that the majority (6 out of 9) expects no or only a minor impact (less than 10\% changes). This means that size and industry sector are lesser contingencies for process prioritisation based on enterprise strategy. However, some respondents clarified that they believe the priority of the process would remain largely identical given industry or size variations, but that the complexity of the implementation of the process would be varying. As for the results of the mapping, these results need to be confirmed or further researched in a larger scale test.

\subsubsection{Sensitivity Analysis}

Referring to the original purpose of introducing the new construct 'enterprise strategy', we now need to establish whether the newly proposed mapping between 'enterprise strategies' and processes indeed results in a more sensitive prioritisation mechanism.

\section{Figure 9. Process weights range across all enterprise strategy combinations}

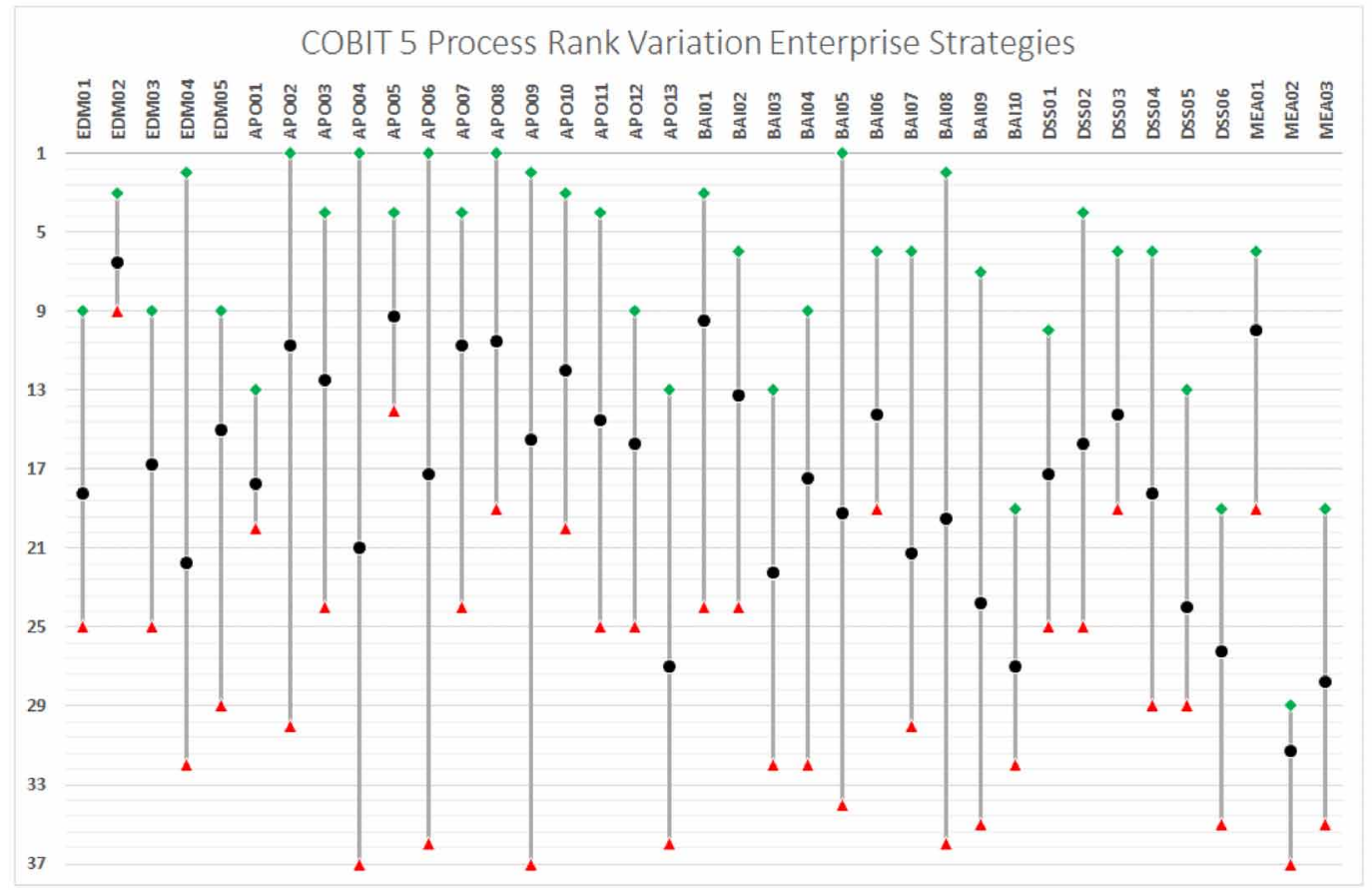


We tested the new construct in the goals cascade by using the set of enterprise strategies as our independent variable. Considering that many organisations use hybrid strategies, we created a set of possible scenarios of combinations to what extent an organisation can apply an enterprise strategy, or a combination thereof. We used increments of $25 \%$, which leads to 35 possible combinations of enterprise strategies.

We applied all these variations to the mapping table (Table 6), and we then observed the resulting values for the process weights. The results of this simulation and measurement are included in Figure 10 (process weights range across enterprise strategy variations) and Figure 11 (process ranking across enterprise strategy variations.

Finally, we compare the observed sensitivity to the currently published Goals Cascade. This is shown in Figure 12, where we compare maximum process ranking variations for both goals cascades.

\section{DISCUSSION}

\subsection{Discussion on Accuracy of the Goals Cascade}

From the above we can conclude that (1) our proposition is validated, i.e. there are significant deviations in resulting process weights and relative process rankings from the use of both sets of mapping tables, and (2) that due to the rounding of the research data values in the published mapping tables, an imprecision has been introduced, leading to an average inherent inaccuracy of around $11 \%$, in the process weights obtained through the use of the goals cascade, with actual values ranging between $0 \%$ and $42 \%$.

Looking at the nature of the reduction of the research data into published mapping tables, i.e. reduction of a continuum of values in the interval $[0 . .1]$ to three discrete values $[0,1 / 2,1]$, differences of the observed order of magnitude of the Goals Cascade output were to be expected. The explanation of the more extreme deviations, lies in the development process of the COBIT 5 Framework itself,

Table 6. Mapping table between enterprise strategies and Cobit 5 processes

\begin{tabular}{|c|c|c|c|c|c|c|c|c|c|c|c|c|c|}
\hline & EDM01 & EDM02 & EDM03 & EDM04 & EDM05 & & & & & & & & \\
\hline ESO1 & 4,7 & 5,3 & 5,3 & 4,3 & 5,3 & & & & & & & & \\
\hline ESO2 & 4,0 & 6,7 & 4,0 & 3,7 & 6,0 & & & & & & & & \\
\hline $\mathrm{ESO} 3$ & 5,3 & 5,3 & 5,0 & 8,0 & 4,0 & & & & & & & & \\
\hline \multirow[t]{2}{*}{ ESO4 } & 5,0 & 7,3 & 5,0 & 4,7 & 5,3 & & & & & & & & \\
\hline & APO01 & APO02 & APO03 & APO04 & APO05 & APO06 & APO07 & APO08 & APO09 & APO10 & APO11 & APO12 & APO13 \\
\hline ESO1 & 4,7 & 7,3 & 6,7 & 5,3 & 5,3 & 5,0 & 6,7 & 6,0 & 3,3 & 4,7 & 4,7 & 5,0 & 3,7 \\
\hline ESO2 & 4,3 & 7,3 & 5,7 & 9,0 & 7,0 & 5,0 & 6,0 & 5,3 & 4,3 & 4,3 & 6,0 & 4,0 & 4,0 \\
\hline ES03 & 4,7 & 5,3 & 5,3 & 3,0 & 5,0 & 9,3 & 6,0 & 4,7 & 6,7 & 7,7 & 4,3 & 5,3 & 3,7 \\
\hline \multirow[t]{2}{*}{ ESO4 } & 5,3 & 4,3 & 4,7 & 2,7 & 5,7 & 3,3 & 4,7 & 8,0 & 7,7 & 6,3 & 7,0 & 5,3 & 5,3 \\
\hline & BIA01 & BAI02 & BAI03 & BAI04 & BAI05 & BA106 & BAI07 & BA108 & BAI09 & BAI10 & & & \\
\hline ESO1 & 7,0 & 5,3 & 4,0 & 5,3 & 7,3 & 6,3 & 4,7 & 5,0 & 4,7 & 4,0 & & & \\
\hline ESO2 & 6,3 & 6,3 & 4,3 & 3,7 & 6,0 & 5,7 & 6,3 & 7,7 & 3,3 & 3,7 & & & \\
\hline ES03 & 6,3 & 5,0 & 4,3 & 4,7 & 3,7 & 4,7 & 4,0 & 3,3 & 5,7 & 4,3 & & & \\
\hline \multirow[t]{2}{*}{ ESO4 } & 4,7 & 4,7 & 5,3 & 5,7 & 4,0 & 5,0 & 4,3 & 4,7 & 4,0 & 5,0 & & & \\
\hline & DSS01 & DSSO2 & DSSO3 & DSSO4 & DSS05 & DSS06 & & & & & & & \\
\hline ES01 & 4,7 & 4,7 & 5,0 & 4,7 & 4,3 & 4,0 & & & & & & & \\
\hline ESO2 & 4,0 & 4,0 & 5,0 & 4,7 & 4,0 & 3,3 & & & & & & & \\
\hline ES03 & 5,0 & 5,0 & 4,7 & 4,0 & 4,0 & 4,7 & & & & & & & \\
\hline \multirow[t]{2}{*}{ ESO4 } & 5,7 & 7,0 & 6,3 & 6,3 & 5,3 & 5,0 & & & & & & & \\
\hline & MEA01 & MEA02 & MEA03 & & & & & & & & & & \\
\hline ESO1 & 5,7 & 4,3 & 4,0 & & & & & & & & & & \\
\hline ESO2 & 4,3 & 2,7 & 4,3 & & & & & & & & & & \\
\hline ES03 & 5,7 & 4,0 & 4,3 & & & & & & & & & & \\
\hline ESO4 & 6,3 & 4,3 & 3,7 & & & & & & & & & & \\
\hline
\end{tabular}


International Journal of IT/Business Alignment and Governance

Volume 7 • Issue 2 • July-December 2016

Figure 10. Process weights range across all enterprise strategy combinations

COBIT 5 Process Weights obtained through Enterprise Goals - Process

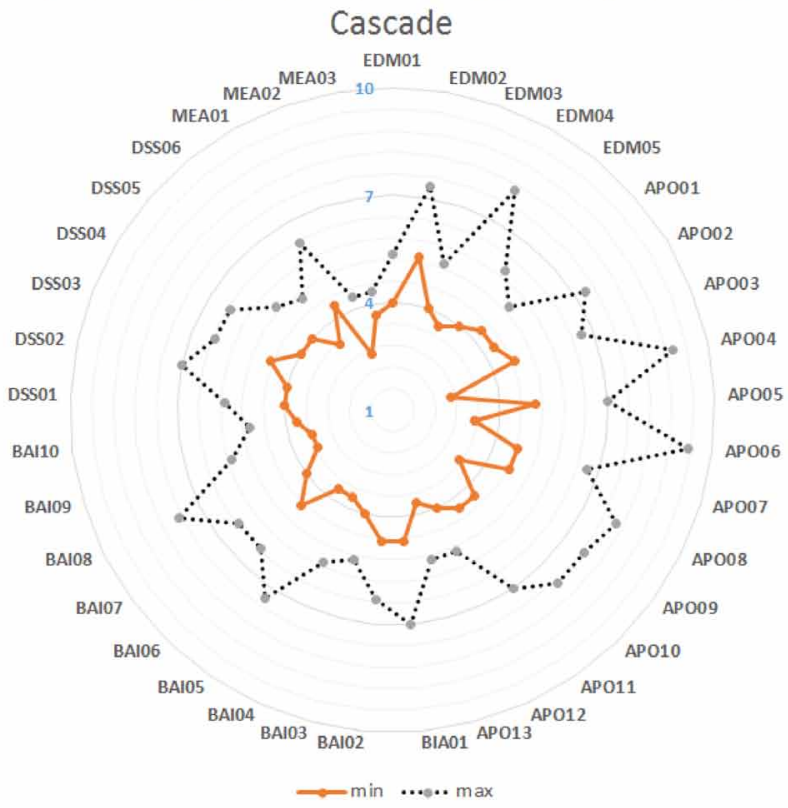

Figure 11. Process ranking range across all enterprise strategy combinations

COBIT 5 Process Ranking obtained through Enterprise Strategies - Goals

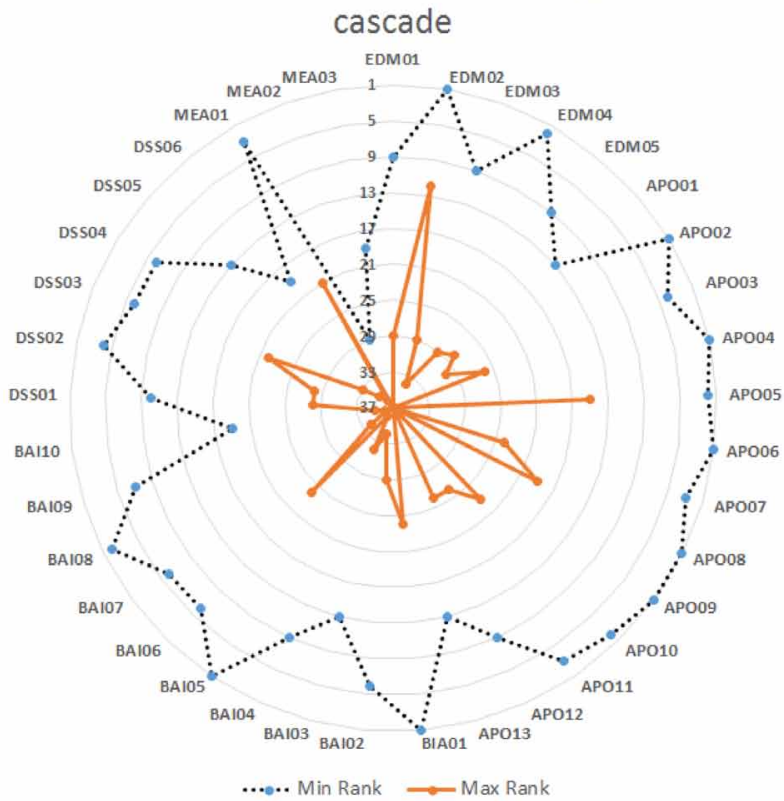




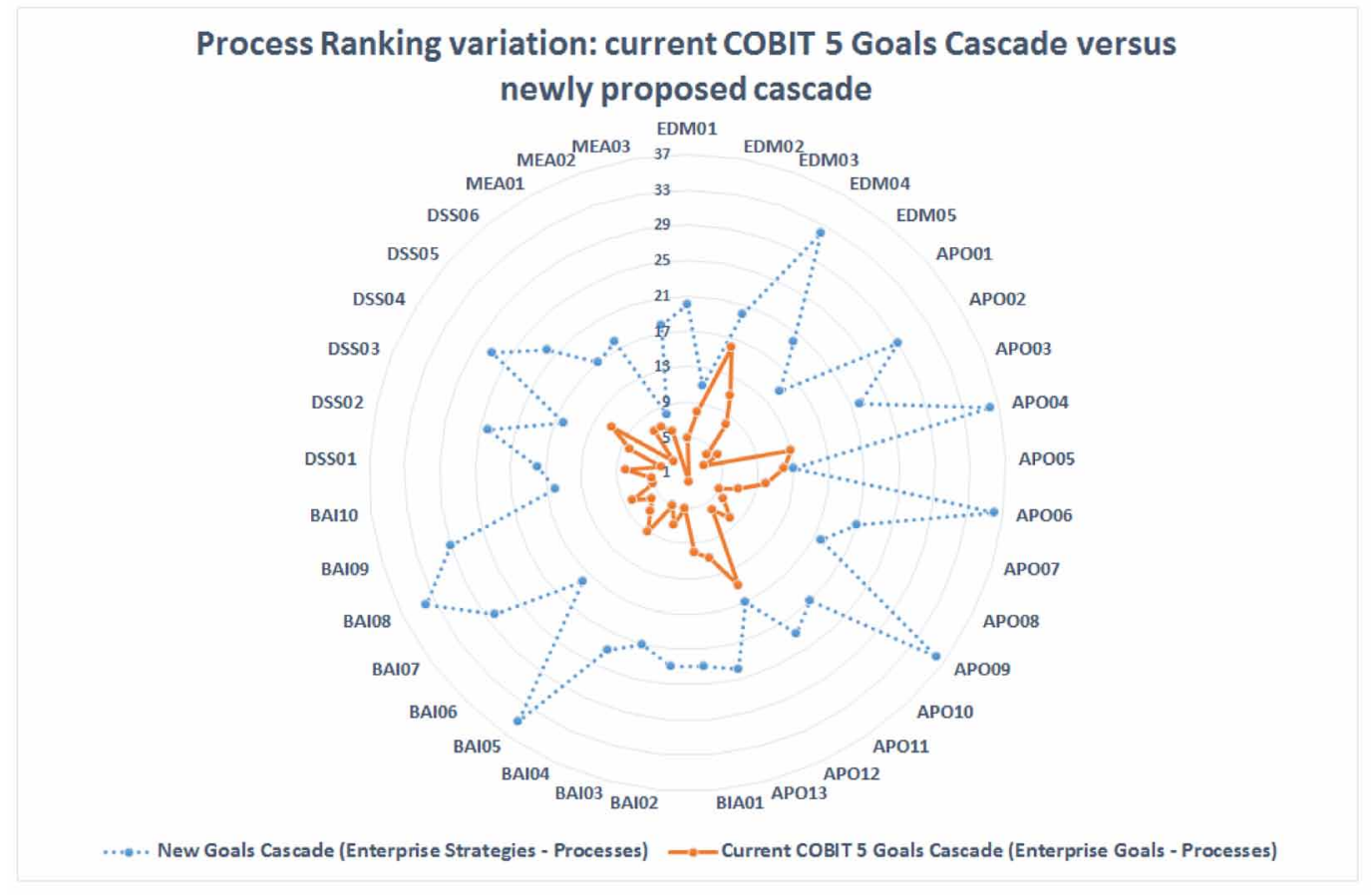

where the original research data of the mappings has been manually modified upon independent review before publication. We do not know about the reason for such changes or the data that underlies them.

One could argue that finding deviations in absolute values for process weights is not per se an indication of weak usability for process prioritisation, as long as the relative ranking of processes would be maintained across the use of both mapping set tables. But there also, we observed some important differences between the uses of both sets of mapping tables, in line with the results of the comparison of process weights; $41 \%$ of the processes have a ranking difference higher or equal than 5 , which we consider to be a significant impact.

\subsection{Discussion on Goals Dependencies}

The observation that the set of goals in the COBIT 5 Enterprise Goals contains hierarchical dependencies: (1) is not earth-shattering because a set of balanced scorecard-based goals is by definition interdependent, (2) implies that it is not possible to make independent priority scoring of the different goals. Assigning a certain priority score to a goal would require assigning at least the same priority to all contingent goals, as well as all further contingent goals. In practice, this means that many, if not all goals, will have to have the same priority, making the prioritisation exercise almost meaningless.

We can conclude that our proposition is confirmed, and that - for easier prioritisation purposes - a set of less interdependent goals should be developed.

\subsection{Discussion on Goals Cascade Sensitivity}

When looking at the simulation results of process weight variation, we observe that - except very few cases - the process weight variation is limited; the average variation over all processes between maximum and minimum process weight is 1,3 . 
When looking at process ranking variation, we observe that (a) the average process ranking variation is 7, 3, which is limited, and (b) when looking at the banded zones on Figure 4, a majority of processes will always remain in the same band, e.g.no matter how much the independent variable changes, the same 10 processes will always remain in the top-12 of highest ranked processes. Likewise, for the bottom processes.

The results of our simulations show that the sensitivity of the Goals Cascade is low:

1. Process weights hardly change with varying enterprise goal priorities; for a number of processes the observed variation does not even exceed the inherent inaccuracy of the process weight.

2. Process rankings vary even less with varying enterprise goal priorities - processes will consistently remain in the same group of high/medium/low priority process irrespective of the enterprise goal priorities

In conclusion we can state that our proposition is confirmed, i.e. the current goals cascade in COBIT 5 is not sensitive enough to enterprise goal priority variations for it to allow meaningful process prioritisation.

\subsection{Discussion on Proof of Concept of the new 'Enterprise Strategies' Artefact}

We observe a significant spread in relative process ranking across enterprise strategies:

1. The average variation between minimum and maximum rank for the same process between enterprise strategies is 20 , on a total of 37 processes. This indicates that the same process can be ranked significantly lower or higher depending on the enterprise strategy. This compares to an average variation of 7.4 for the current Goals Cascade (Table 3).

2. The maximum differences observed between minimum and maximum ranking for one process are 36 (process APO04 - Manage Innovation) and 35 (processes APO06 - Manage budget and cost and APO09 - Manage Service Agreements), showing an extreme variance from being the most important process under one enterprise strategy and the least important process under a different enterprise strategy. This compares to a maximum variation of 15 for the current Goals Cascade (Table 3).

As for the sensitivity analysis, in Figure 10 we can observe that variations in process weights depending on the enterprise strategy mix are meaningful; in Figure 11 we can observe a very significant spread in process ranking, indicating a high sensitivity on process rank as output of the new goals cascade application.

From Figure 12, it is obvious that the newly proposed goals cascade between enterprise goals and processes is much more sensitive to input variations than the current Goals Cascade, thus fulfilling our requirement for the new construct 'enterprise goals'. The average ranking variation in the newly proposed goals cascade is three times higher ( 22 versus 7,3$)$ compared to the currently published Goals Cascade.

From all the previous we can conclude that:

1. We have introduced a new construct 'enterprise strategies, which contains a limited number of independent values, and yet is comprehensive in its covering of all potential enterprise strategies;

2. We have obtained an indication that the mapping between the new construct 'enterprise strategy' and the existing COBIT 5 processes is feasible and meaningful;

3. A goals cascade using the newly proposed construct 'enterprise strategy' is three times more sensitive than the currently existing Goals Cascade. 
The last finding is to a certain extent as could be expected, because we essentially replaced a two-step cascade in COBIT 5 (from enterprise goals to IT related goals, and from IT Related Goals to Process Goals) by a one-step cascade (from Enterprise Strategies to Process Goals), using a much simpler mapping matrix. But we argue that this is not necessarily a problem, as long as the mapping is proven valid, i.e. that there is a demonstrable influence of IT process achievement on successful execution of chosen enterprise strategies. This point will be part of follow-on research.

\section{OVERALL CONCLUSION, LIMITATIONS AND CONTRIBUTION}

From the research described in this paper, we can conclude that the COBIT 5 Goals Cascade in its current form is not a well suited process prioritisation tool.

This is substantiated by our findings that the current goals cascade is inherently inaccurate, contains too many goal interdependencies, and its outputs in the form of process weights and/or rankings are almost insensitive to input variations.

We proposed the introduction of a new construct 'enterprise strategy' into the Goals Cascade, with an associated mapping table, allowing for a much more sensitive process prioritisation.

We believe that our contribution to the knowledge field consist of a first instance of research of COBIT 5 as an artefact (De Haes et al, 2013), resulting in a proposed enhancement to one of COBIT 5's main constructs.

The limitations of our research include (1) the newly proposed construct is a proof of concept, requiring confirmation, and (2) having a sensitive prioritization tool is an improvement over the current goals cascade-based prioritization, but before adoption that actual set of enterprise goals and their mapping to processes needs more validation.

\section{FURTHER RESEARCH}

Further research on the topic of our paper is both possible and much recommended, e.g.

1. More extensive and rigorous confirmation of our initial set of enterprise strategy values and the mapping table between enterprise strategies and COBIT 5 processes

2. Potential extension of the research to other enablers as identified in COBIT 5, e.g.; organisational structures, people \& skills

3. Including inter-process dependencies as well into the application of the COBIT 5 Goals Cascade;

4. Enterprise strategies seem to be a valid new construct to help prioritise processes; however, there might be others (e.g. business model/operating model,) that would also deserve some further exploration and research.

5. Potential clustering of IT related processes, depending on their overall rated importance and on their variation with enterprise strategies 
International Journal of IT/Business Alignment and Governance

Volume 7 • Issue 2 • July-December 2016

\section{REFERENCES}

Ansoff, H. (1965). Corporate Strategy. New York: McGraw-Hill.

Bartens, Y., De Haes, S., Lamoen, Y., Schulte, F., \& Voss, S. (2015). On the Way to a Minimum Baseline in IT Governance: Using Expert Views for Selective Implementation of COBIT 5. Proceedings of the $48^{\text {th }}$ HICSS Conference, Hawaii, USA. doi:10.1109/HICSS.2015.543

Bartens, Y., Schulte, F., \& Voss, S. (2014). E-Business IT Governance Revisited: An Attempt towards Outlining a Novel Bi-directional Business/IT Alignment in COBIT5. Proceedings of the $47^{\text {th }}$ HICSS Conference. doi:10.1109/ HICSS.2014.538

Chan Kim, R. (2005). Mauborgne, Blue Ocean Strategy. USA: Harvard Business Review Press.

De Haes, S., Huygh, T., Joshi, A., Van Grembergen, W. (2016). Adoption and Impact of IT Governance and Management Practices: A COBIT 5 Perspective. International Journal of IT/Business Alignment and Governance, $7(1)$.

De Haes, S., Van Grembergen, W., \& Debreceny, R.S. (2013). COBIT 5 and Enterprise Governance of Information Technology: Building Blocks and Research Opportunities. Journal of Information Systems, 27(1), 307-324.

ISACA. (2012). COBIT 5 A Framework for the Governance and Management of Enterprise IT.

ISACA. (2012). COBIT 5 Enabling Processes.

ISACA. (2014). COBIT 5 Enabling Information.

Iskandar, M., \& Salleh, N. A. M. (2010). IT Governance in Airline Industry: A Multiple Case Study. International Journal of Digital Society, 1(4), 308-313. doi:10.20533/ijds.2040.2570.2010.0037

Kaplan, R. S., \& Norton, D. P. (2004). "Having Trouble with Your Strategy? Then Map It", Focussing Your Organization on Strategy - with the Balanced Scorecard (2nd ed.). Harvard Business Review OnPoint Collection.

Laksonto, H., \& Supriyadi, Y. (2015). Design and Implementation Information Security Governance Using Analytic Network Process and COBIT 5 for Information Security - A Case Study of Unit XYZ.Proceedings of ICITSI ' 15 , Bandung.

Mai, J.-E. (2013). The Quality and Qualities of Information. Journal of the American Society for Information Science and Technology, 64(4), 675-688. doi:10.1002/asi.22783

Mangalaraj, G., Singh, A., \& Taneja, A. (2014). IT Governance Frameworks and COBIT - A literature Overview. Proceedings of theTwentieth Americas Conference in Information Systems, Savannah, USA.

Miles, R.E., \& Snow, C.C. (2015, June). Organizational strategy, structure, and process, Stanford University Press, Stanford.

PorterM. (1980). Competitive Strategy.USA.

Reeves, M., Haanaes, K., \& Sinha, J. (2003). Navigating the Dozens of Different Strategy Options. Harvard Business Review.

Romadhona, A., \& Arman, A. A. (2015, November). An Analysis of Information Technology Governance Case Study: Statistics Indonesia. Proceedings of the2015 International Conference on Information Technology Systems and Innovation, Bandung-Bali. doi:10.1109/ICITSI.2015.7437733

Supriyadi, Y. (2015). Design of IT Governance Implementation Mechanism Using Organization Diagnosis and COBIT 5. Proceedings of the $3^{\text {rd }}$ Information Systems International Conference, Open Access Journal of Information Systems.

Textor, A., \& Geihs, K. (2015). Calculation of COBIT Metrics Using a Formal Ontology. Proceedings of the $10^{\text {th }}$ International Workshop on Business-driven IT Management IFIP/IEEE IM '15. doi:10.1109/INM.2015.7140501 
Treacy, M., \& Wiersema, F. (1993). The Discipline of Market Leaders. USA.

Wernerfelt, B. (1984). A Resource-Based View on the firm. Strategic Management Journal, 5(2), 171-180. doi:10.1002/smj.4250050207

\section{ENDNOTES}

COBIT 5 processes APO13, BAI9 and DSS3 were added to the COBIT 5 Process Reference Model after completion of the research on the Goals Cascade and hence no original research mapping data are available for those processes. 